\title{
Biopsy findings in malignant histiocytosis presenting as lethal midline granuloma
}

\author{
K AOZASA
}

From the Department of Pathology, Faculty of Medicine, Osaka University, Osaka, Japan

SUMMARY Nasal biopsy findings in malignant histiocytosis presenting clinically as lethal midline granuloma are characterised by necrosis and infiltration of atypical histiocytic cells with a diffuse positive reaction for non-specific esterase. This cellular character was common to midline malignant reticulosis, and midline malignant reticulosis and malignant histiocytosis are thought to be the same disease.

Patterns of histiocytic infiltration in the nasal lesions of 19 cases are reported in this paper. Polymorphic and monomorphic patterns were observed in 11 and four cases respectively, on the initial biopsy, but subsequently the infiltrates frequently became monomorphic on serial biopsy. The reverse was not observed. Surface marker and cytochemical studies showed the true histiocytic nature of the proliferating cells, and necropsy findings justified the diagnosis of malignant histiocytosis.

Six necropsy cases with malignant histiocytosis (MH) presenting as lethal midline granuloma (LMG) have been previously reported by us. ${ }^{1}$ The histological features of the nasal lesions in these cases were necrosis and polymorphic cellular infiltrates of atypical histiocytic cells with diffuse positive reactions for alpha-naphthyl acetate and butyrate esterase. It was suggested that midline malignant reticulosis, in which nasal lesions were characterised by a mixture of lymphoid cells and atypical reticulum cells often with bizarre nuclei, ${ }^{2-4}$ and malignant histiocytosis might be the same disease process. Subsequently, the appearance of a monomorphic infiltrate during the serial biopsy of malignant histiocytosis was reported by us. ${ }^{5}$ Even in this instance, tumour cells in malignant histocytosis can be differentiated from those in other lymphomas by cytological and cytochemical findings. ${ }^{56}$ It was proposed that lymphoreticular neoplasia in the nose should be divided into lymphocytic and true histiocytic neoplasia.

In this paper, 19 cases with lethal midline granuloma selected by the presence of atypical histiocytic cells in the biopsies from nose and adjacent structures are reviewed to investigate the pattern of histiocytic infiltration. Necropsy findings are identical with those of malignant histiocytosis. ${ }^{7}$

Accepted for publication 23 March 1981

\section{Material and methods}

The 19 cases being reported are patients hospitalised in 1965-78. The clinical findings were similar to those in lethal midline granuloma. Thirty biopsies were obtained from the nasal or adjacent structures (or both) in these patients, and serial biopsies were available in seven cases. The total number of specimens obtained was 42. Paraffin sections from the 19 cases were stained with haematoxylin and eosin. All patients died, and necropsy was done on 10 patients.

Fresh materials were available in three cases: lymph node (case 14), subcutaneous nodule (case 17) and nasal lesion (case 19) (Table). In these surface markers were studied by the estimation of percentage of the cells forming spontaneous $\mathrm{E}$ rosettes and the cells bearing surface immunoglobulin (S-Ig). ${ }^{8}$ Imprint smears were stained with alpha-naphthyl acetate and butyrate esterase ${ }^{9}$ and acid phosphatase. ${ }^{10}$ Ability of latex phagocytosis by histiocytic cells was tested in one case (case 14). ${ }^{11}$

\section{Results}

Specimens were divided into four groups according to the manner of histiocytic infiltration: monomorphic pattern (MM) (Figs 1 and 2), polymorphic pattern (PM)(Figs 3 and 4), inflammatory lesions with- 
Histological findings of biopsy material from nasal lesions in 19 cases

\begin{tabular}{|c|c|c|c|c|c|c|c|}
\hline \multirow[t]{2}{*}{ Case } & \multirow[t]{2}{*}{ Sex } & \multirow[t]{2}{*}{ Age } & \multicolumn{4}{|c|}{ Biopsy findings } & \multirow[t]{2}{*}{ Survivals (months) } \\
\hline & & & First & Second & Third & Fourth & \\
\hline 1 & $M$ & 45 & PM & & & & 4 \\
\hline 2 & $\mathrm{M}$ & 45 & $\mathrm{MM}$ & MM & & & 4 \\
\hline 3 & $M$ & 40 & $\mathrm{~N}$ & & & & 4 \\
\hline 4 & $\mathrm{~F}$ & 59 & PM & & & & 5 \\
\hline 5 & $M$ & 81 & $\mathrm{PM}$ & & & & 5 \\
\hline 6 & $\mathrm{M}$ & 44 & $\mathrm{MM}$ & & & & 6 \\
\hline 7 & $\mathrm{M}$ & 38 & $\mathbf{P M}$ & & & & 6 \\
\hline 8 & $\mathbf{M}$ & 57 & PM & & & & 6 \\
\hline 9 & $\mathrm{~F}$ & 50 & PM & $\mathbf{M M} / \mathbf{P M}$ & & & 8 \\
\hline 10 & $\mathbf{M}$ & 24 & $\mathbf{M M} / \mathbf{P M}$ & & & & 12 \\
\hline 11 & $\mathbf{M}$ & 22 & PM & & & & 13 \\
\hline 12 & $\mathbf{F}$ & 40 & $\mathrm{~N}$ & & & & 16 \\
\hline 13 & $\mathrm{M}$ & 74 & PM & & & & 17 \\
\hline 14 & $\mathrm{~F}$ & 36 & PM & & & & 21 \\
\hline 15 & $\mathrm{~F}$ & 23 & MM & $\mathbf{M M}$ & & & 22 \\
\hline 16 & $\mathrm{M}$ & 26 & PM & PM & $\mathbf{M M}$ & & 24 \\
\hline 17 & $\mathbf{M}$ & 37 & $\mathrm{~N}$ & PM & $\mathbf{P M} / \mathbf{M M}$ & & 24 \\
\hline 18 & $\mathbf{M}$ & 18 & IC & $\mathbf{M M} / \mathbf{P M}$ & & & 26 \\
\hline 19 & $\mathbf{M}$ & 49 & PM & IC & $\mathbf{M M} / \mathbf{P M}$ & $\mathbf{M M} / \mathbf{P M}$ & 40 \\
\hline
\end{tabular}

$\mathrm{PM}=$ polymorphic pattern, $\mathrm{MM}=$ monomorphic pattern, $\mathrm{N}=$ necrosis, $\mathrm{IC}=$ inflammatory change .

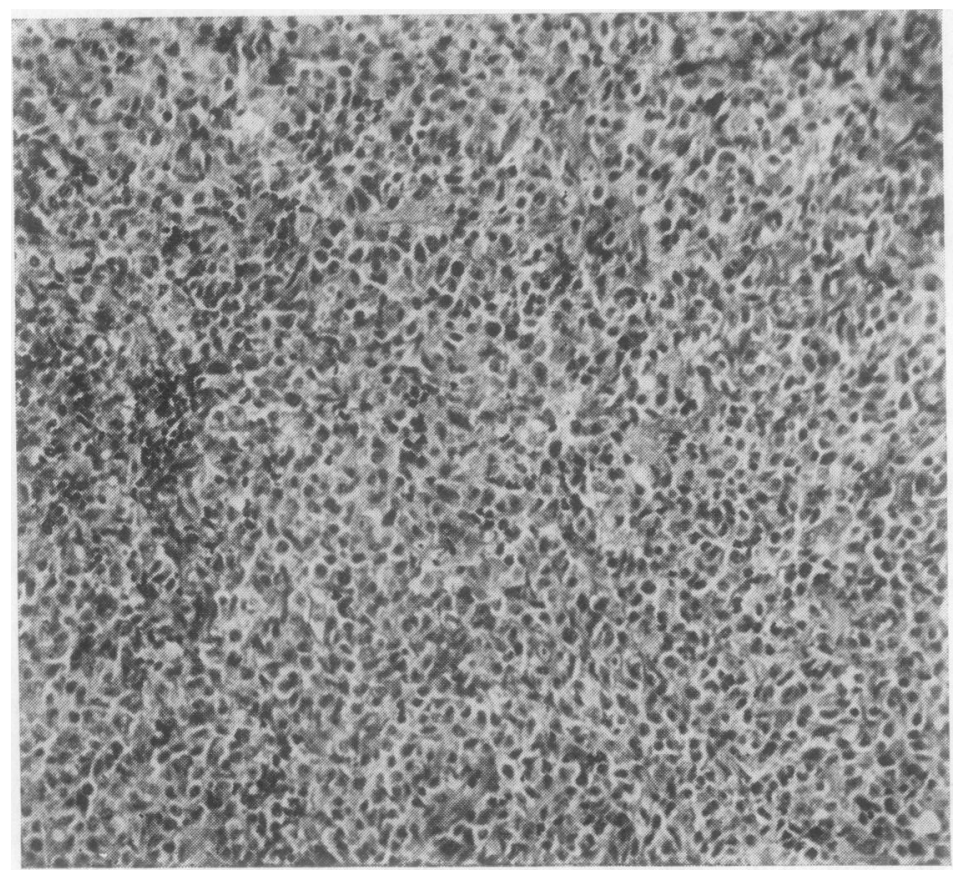

Fig. 1 Monomorphic pattern with compact appearance. There are several bleeding foci in the field. Haematoxylin and eosin $\times 200$.

out infiltration of atypical histiocytes (IC) and coagulative necrosis containing atypical cells $(\mathrm{N})$. When both polymorphic and monomorphic patterns were observed in one specimen or in several specimens obtained simultaneously, the findings were expressed as follows: when a monomorphic pattern was dominant "MM/PM" and when a polymorphic pattern was dominant, "PM/MM". The results of histological study are shown in the Table.

The histiocytic cells were composed of three morphological types: normal appearing forms; large atypical forms with a single nucleus; and multinucleated forms. The large atypical form dominated in the monomorphic infiltrates and the other two forms were generally not marked (Fig. 2). All three forms intermingled with lymphocytes, 


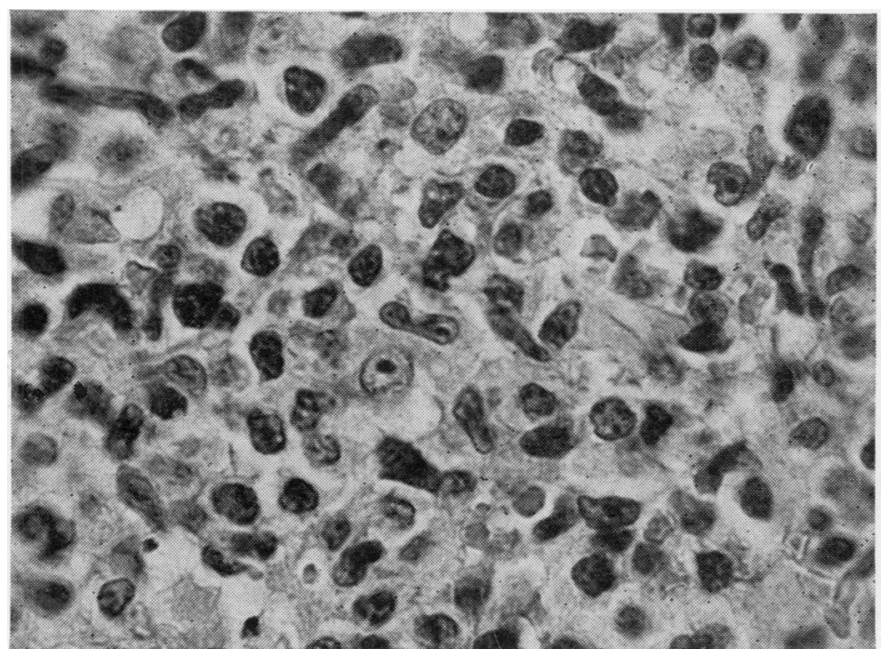

Fig. 2 Cytological details of Fig. 1. Large atypical cells are arranged compactly, and cell borders are unclear. Indented, folded or lobulated nuclei with thick and clear nuclear membranes show hyperchromatism, in which one to several nucleoli are observed. Cytoplasm is rich, eosinophilic and occasionally vacuolated. Haematoxylin and eosin $\times 700$.

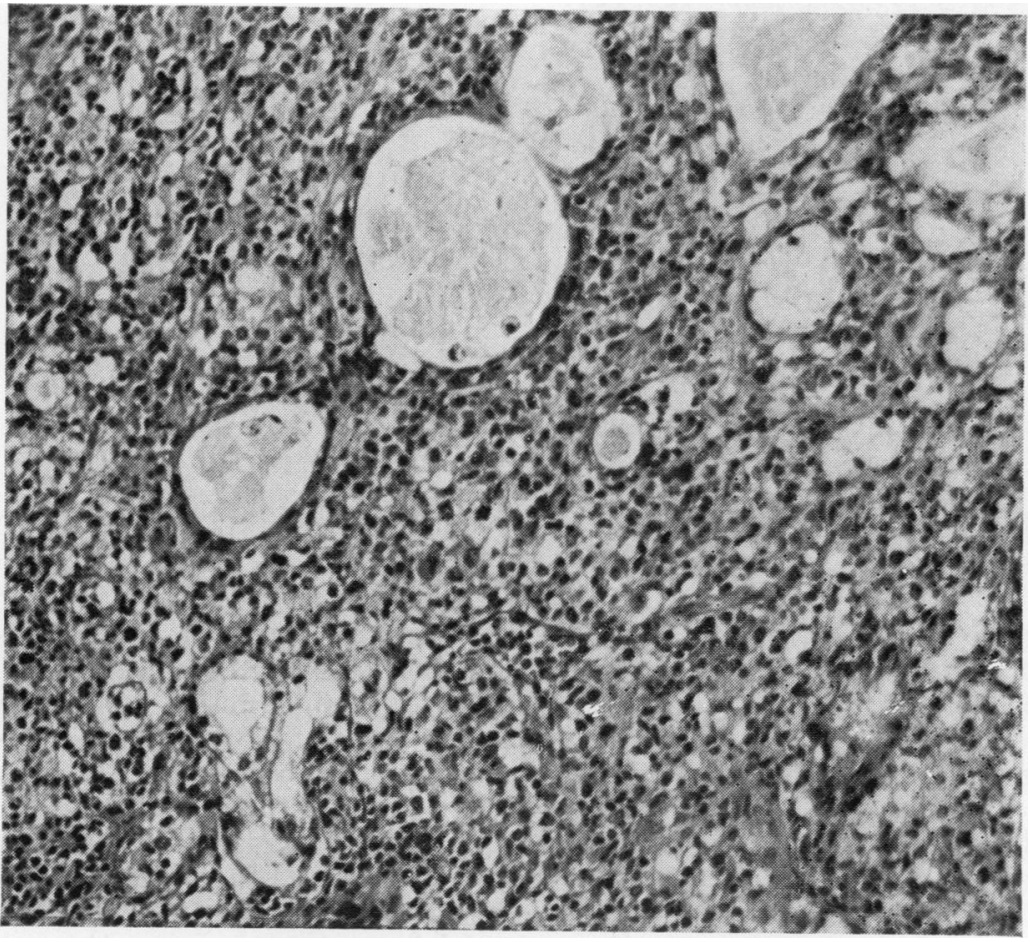

Fig. 3 Polymorphic pattern. Submucosal glands are preserved. Haematoxylin and eosin $\times 200$. plasma cells and neutrophils were frequently seen in polymorphic infiltrates. (Fig. 4). Mitotic figures and phagocytosis were more frequent in monomorphic infiltrates (Fig. 5). Perivascular infiltration by atypical histiocytes was the characteristic feature both in mono- and polymorphic infiltrates. Even in the former, submucosal glands were relatively well preserved.

In the initial biopsy, the numbers of cases showing monomorphic, polymorphic, inflammatory and necrotic patterns were 4, 11, 1 and 3, respectively. In four cases (case $9,16,17,19$ ), the infiltrates changed 


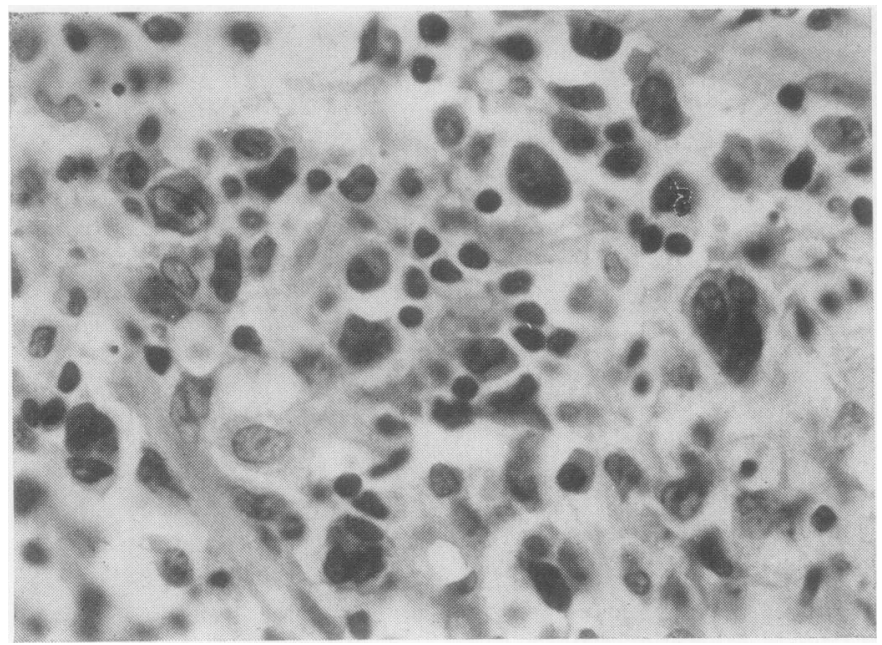

Fig. 4 Cytological details of Fig. 3. Single and multinucleated large cells intermingled with lymphocytes and plasma cells. Haenatoxylin and eosin $\times 700$.

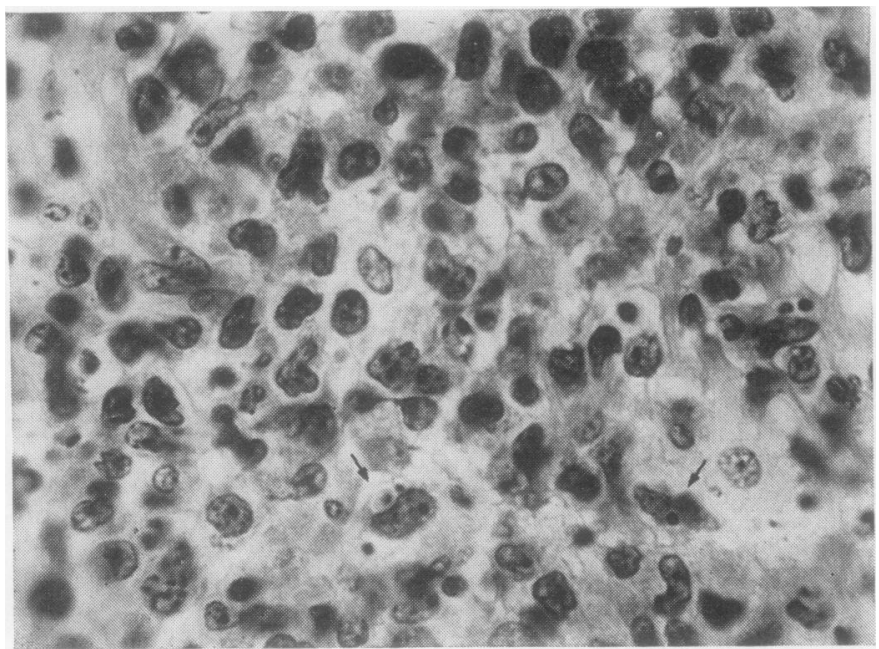

Fig. 5 Phagocytic figures in almost monotonous proliferation (arrows). Haematoxylin and eosin $\times 700$.

from a polymorphic to a monomorphic infiltrate in subsequent biopsies. No cases showed a transition from the monomorphic to polymorphic form. The first biopsy of one case (case 18) showed an inflammatory pattern, but in the subsequent biopsy a monomorphic pattern was dominant. Mature histiocytes with foamy cytoplasm were noticed in two specimens showing a monomorphic pattern (cases 10, 16) and in one with a polymorphic pattern (case 8) (Fig. 6). All these specimens were obtained after chemotherapy or combined chemotherapy and radiation.

In $69 \%$ of the specimens with a polymorphic or inflammatory pattern, acanthosis of the metaplastic respiratory epithelium was observed. Squamous metaplasia of submucosal glands was observed in $27 \%$. In about half of the specimens, capillaries with swollen endothelium were abundant in the fields. Although a thrombus was occasionally formed in arterioles, capillaries and venules, necrosis or neutrophilic infiltration of the vascular walls was infrequent. Generally, these findings were found near the necrosis.

Results of surface marker studies were as follows; $E$ rosette forming cells ranged from 0 to $17 \%$ and S-Ig bearing cells ranged from 5 to $10 \%$. Both nonspecific esterase (alpha-naphthyl acetate and butyrate esterase) and acid phosphatase reaction revealed diffuse positivity in the cytoplasm of atypical histiocytes. Positive reaction for alpha-naphthyl acetate was suppressed by $0.15 \%$ sodium fluoride. Many large cells showing positive reaction for nonspecific esterase actively phagocytosed latex particles in one case. The histological findings in the 10 


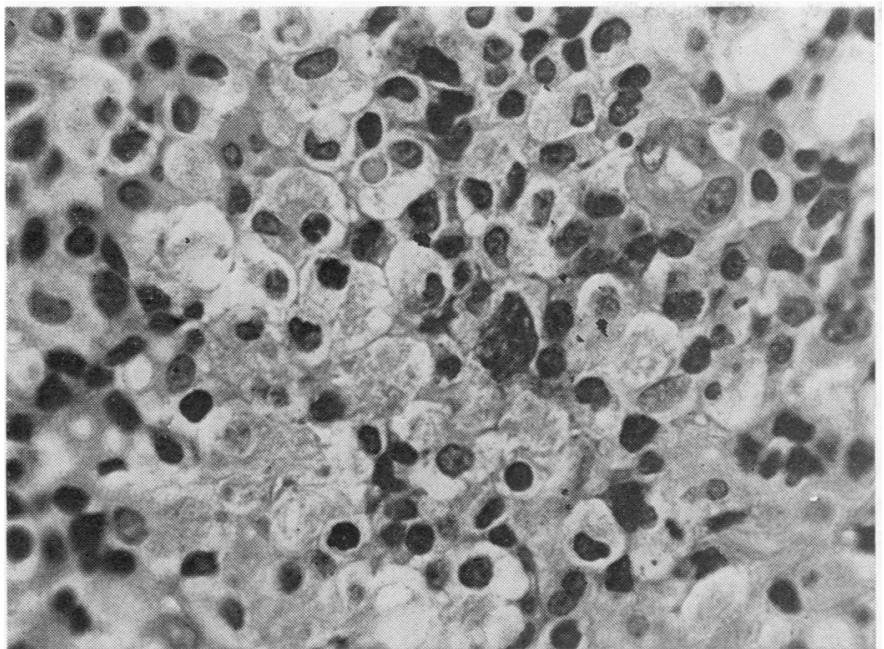

Fig. 6 Appearance of mature histiocytes with foamy cytoplasm. Erythrophagocytosis is seen in the upper centre. Haematoxylin and eosin $\times 620$.

necropsies were systemic and diffuse proliferation of atypical histiocytes (Fig. 7).

\section{Discussion}

The view that midline malignant reticulosis is a malignant neoplasm of lymphoreticular cells, and is a variant of malignant lymphoma ${ }^{312}$ has been popular. In 1977, Michaels and Gregory reported biopsy and necropsy findings in 10 cases with midline malignant reticulosis. ${ }^{13}$ Biopsy findings were necrosis with atypical cellular exudate. There was feeble chromatin production and evidence of phagocytosis in these atypical cells. They classified these 10 cases as "histiocytic" lymphoma. In one case, malignant histiocytosis particularly was suspected because of marked erythrophagocytosis and the pattern of organ involvement found at necropsy.

Six cases of malignant histiocytosis presenting as lethal midline granuloma have recently been reported by us. ${ }^{1}$ These cases were diagnosed as malignant histiocytosis by the characteristic necropsy findings of systemic and non-tumorous proliferation of atypical histiocytes. ${ }^{7}$ Necropsy findings in the present 10 cases were of malignant histiocytosis. Biopsy findings were those reported in malignant midline reticulosis and alpha-naphthyl acetate and butyrate esterase reactions confirmed the histiocytic nature of the proliferating cells. ${ }^{15}$ It is suggested that malignant midline reticulosis and malignant histiocytosis may be the

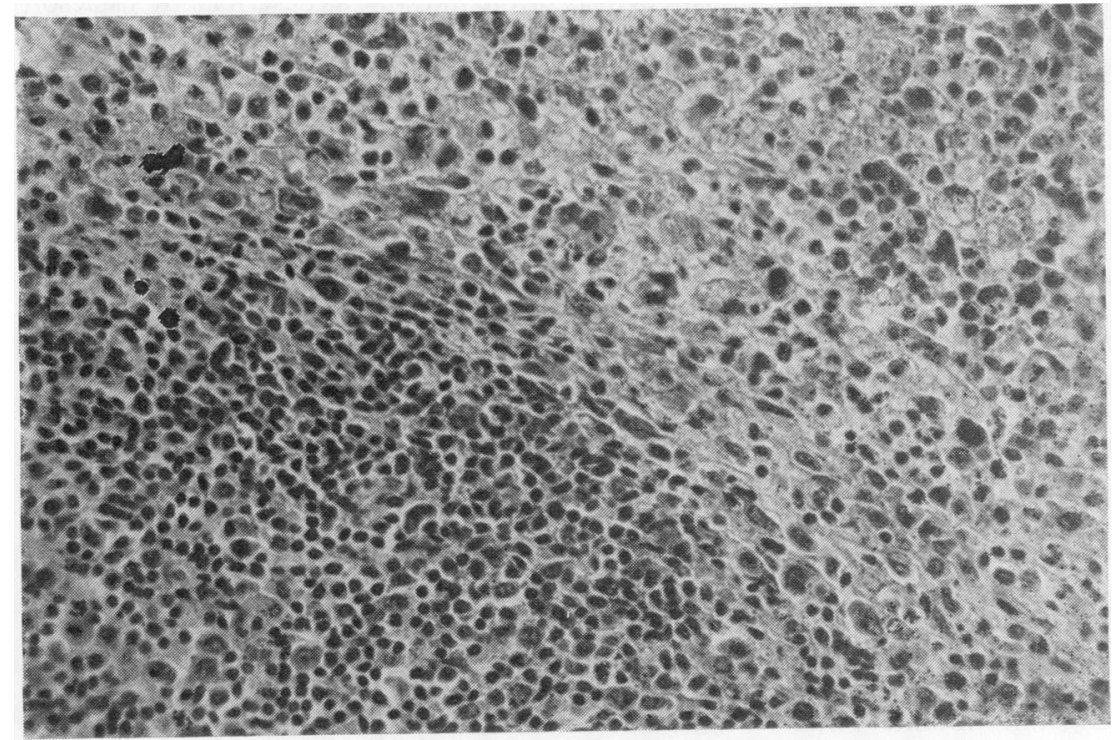

Fig. 7 Spleen affected $b_{y}$ the terminal malignant histiocytosis. Atypical histiocytes mainly proliferated in the red pulp. Haematoxylin and eosin $\times 260$. 
same disease caused by neoplastic proliferation of true histiocytes.

Although malignant midline reticulosis has been diagnosed because of the polymorphic character of the infiltrates, ${ }^{2-4}$ we have reported transition of the infiltrate from polymorphic to monomorphic during the serial biopsy of a case with malignant histiocytosis. ${ }^{5}$ The case is included in this paper (case 17).

Malignant histiocytosis showing monotonous proliferation may be differentiated from ordinary lymphoma by the cytological findings. Coexistence of normal appearing histiocytes, large mononuclear and multinucleated forms of histiocytes, and those having irregular nuclear configurations with thick and clear nuclear membranes, unevenly distributed chromatin and conspicuous nucleoli, are common findings in malignant histiocytosis, but rare in ordinary lymphomas. ${ }^{5}$ In addition, the reactions for alpha-naphthyl acetate and butyrate esterase reactions gave clear distinction between the two diseases.

A polymorphic infiltrate was the most common pattern of histiocytic infiltration on initial biopsy in 19 cases presented here. However, a monomorphic infiltrate was not so infrequent: three cases of monomorphic pattern and one case of MM/PM at the first biopsy, four cases of polymorphic or inflammatory infiltrate at the first biopsy changed to a monomorphic pattern or mixed infiltrate (MM/PM or $\mathbf{P M} / \mathbf{M M})$. The infiltrates always changed in the direction of a more monomorphic pattern. There was no clear relation between the pattern of histiocytic infiltration and survivals in these cases.

In many reports describing histological and cytological findings of malignant midline reticulosis, ${ }^{2-4} 12$ phagocytosis by the atypical cells is rarely mentioned. In ten cases reported previously, phagocytosed basophilic debris was frequently observed. ${ }^{13}$ In our series, phagocytosis by atypical cells was not so frequent, but was more common in monomorphic than polymorphic infiltrates. Appearance of foamy histiocytes, after the chemotherapy or radiation, or both, suggested the true histiocytic nature of infiltrating cells.

Surface marker and enzyme cytochemical studies carried out in three cases presented here showed that atypical cells were true histiocytic in nature. ${ }^{14-16}$ De Faria et al, using in vivo techniques, demonstrated that a number of monocyte-like cells in the lesion of malignant granuloma had engulfed iron particles. ${ }^{17}$ They called this lesion a reticulohistiocytosarcoma.

Acanthosis of metaplastic epithelium and squamous metaplasia of submucosal glands, observed, respectively, in $69 \%$ and $27 \%$ of our cases, have been reported in malignant midline reticu- losis. ${ }^{2}$ Abundance of capillaries in the background stroma has also been described. ${ }^{12}$ These epithelial and stromal changes suggested the presence of chronic inflammation before the initial biopsy.

The survivals of our cases ranged from 4 to 40 months (mean 13.8 months), and $90 \%$ died within two years of treatment with chemotherapy or combined chemotherapy and radiation. Eichel et al reported a good prognosis of malignant midline reticulosis treated by radiation and nine stage 1 cases had a $100 \%$ five year survival. ${ }^{2}$ In a review of published reports, Fechner and Lamppin ${ }^{3}$ divided 21 acceptable cases with malignant midline reticulosis into two groups, 10 cases of localised disease and 11 cases of disseminated diesase. ${ }^{3}$ The patients who died with disseminated disease survived for two months to 30 months. They reported that the two groups were indistinguishable when only the facial area was involved. Fu and Perzin reported poor response for radiation, and all their cases with follow-up information died due to the tumour. ${ }^{12}$

In conclusion, our 19 cases were characteristic of malignant midline reticulosis in biopsies. Phagocytosis, appearance of foamy histiocytes as well as surface marker and cytochemical findings showed the true histiocytic nature of the lesions. Necropsy findings confirmed the diagnosis of malignant histiocytosis presenting as lethal midline granuloma clinically. At first biopsy, histological findings were more frequently polymorphic and less frequently monomorphic. The former usually changed to the latter. Survivals could not be predicted from the biopsy findings.

The condition is strikingly similar to malignant histiocytosis of the intestine as described by Isaacson and Wright. ${ }^{18} 19$ The presence of villous atrophy with crypt hyperplasia even in the jejunum remote from the areas of ulceration or frank lymphoma was emphasised. They regarded these changes as a prolonged cryptic phase before overt proliferation of atypical histiocytes was manifest.

DIFFERENTIAL DIAGNOSIS

Lethal midline granuloma is a clinical term, and several diseases have been known to be included. ${ }^{4}$ Specific inflammation, tuberculosis, syphilis, and carcinoma can be differentiated from malignant histiocytosis by the clinical and histological findings. Wegener's granulomatosis is usually characterised by generalised necrotising vasculitis involving both arteries and veins and the presence of glomerulitis. ${ }^{20}$ Although arterioles, capillaries and venules were occasionally occluded by thrombus, definite findings suggesting vasculitis were absent in our cases.

Lymphomatoid granulomatosis is an angiocentric and angiodestructive lymphoreticular disorder pre- 
dominantly involving the lungs. ${ }^{21}$ Histologically necrotising angiocentric and angiodestructive infiltrates composed of small lymphocytes, plasma cells, histiocytes and atypical lymphoreticular cells are commonly found.21 22 Crissman reported a patient with midline malignant reticulosis, who eventually developed respiratory failure with lymphomatoid granulomatosis in the lungs. ${ }^{23} \mathrm{He}$ suggested the possibility that the different appearances represent different expressions of the same disease, a form of hypersensitivity vasculitis. In our cases and previously reported cases of malignant midline reticulosis, "perivascular" or "intravascular" infiltration by atypical cells was frequently observed..$^{2} 1213$ Moreover, subendothelial infiltrates are typically observed in lymphomatoid granulomatosis. ${ }^{24}$ Although one report suggested a true histiocytic nature for skin lymphomatoid granulomatosis, ${ }^{25}$ others have noted the plasmacytoid nature of some of the cells. ${ }^{26} 27$ Recently, other investigators, using immunoperoxidase and immunofluorescent techniques, suggested that the disease was B-cell proliferation. ${ }^{24} 28$ In addition, organ involvement shows marked distinction between lymphomatoid granulomatosis and malignant histiocytosis for involvement of reticuloendothelial system is unusual in the former ${ }^{21}$ but is frequent in the latter.

The author thanks Professor $\mathrm{K}$ Matsumoto for reviewing the manuscript, $\mathrm{Mr} \mathrm{A}$ Inoue for technical assistance, and Drs $\mathbf{H}$ Ikeda and $\mathrm{Y}$ Watanabe for clinical information.

\section{References}

${ }^{1}$ Aozasa K, Watanabe Y, Ikeda H. Malignant histiocytosis presenting as lethal midline granuloma. Pathol Res Pract $1981 ; 171: 314-24$.

${ }^{2}$ Eichel BS, Harrison EGJ, Devine KD, Scanlon PW, Brown HA. Primary lymphoma of the nose including relationship to lethal midline granuloma. Am J Surg 1966;112:597-605.

${ }^{3}$ Fechner RE, Lamppin DW. Midline malignant reticulosis. A clinicopathologic entity. Arch Otolaryngol 1973;95: 467-76.

4 Kassel SH, Echevaria RA, Guzzo FP. Midline malignant reticulosis (so-called lethal midline granuloma). Cancer 1969;23:920-35.

${ }^{5}$ Aozasa K, Ikeda H, Masaki N, Watanabe Y. Malignant lymphoma in the nose-Clinicopathological differences from the malignant histiocytosis presenting as lethal midline granuloma. Pathol Res Pract 1981;172:161-9.

${ }^{6}$ Aozasa K, Kurokawa K, Kobori Y, Sawashi Y, Sawada M. Malignant histiocytosis showing ascites and recurrent meningeal infiltration. Acta Cytol 1980;24:228-31.

' Rappaport H. Tumours of the Hematopoietic System.
Atlas of tumour pathology. Washington DC: AFIP, 1966:48-63.

${ }^{8}$ Jondal M, Holm G, Wigzell H. Surface markers on human $T$ and $B$ lymphocytes. I. A large population of lymphocytes forming non-immune rosettes with sheep red blood cells. J Exp Med 1972;136:207-15.

${ }^{9} \mathrm{Li} \mathrm{CY,} \mathrm{Lam} \mathrm{KW,} \mathrm{Yam} \mathrm{LT.} \mathrm{Esterases} \mathrm{in} \mathrm{human} \mathrm{leukocytes.}$ J Histochem Cytochem 1973;21:1-21.

${ }^{10}$ Barka T, Anderson PJ. Histochemical methods for acid phosphatase using hexazonium pararosanilin as coupler. $J$ Histochem Cytochem 1962;10:741-53.

${ }^{11}$ Braylan RC, Jaffe ES, Triche TJ, et al. Structural and functional properties of the "hairy" cells of leukemic reticuloendotheliosis. Cancer $1978 ; 41: 210-27$.

12 Fu Y-S, Perzin KH. Non-epithelial tumours of the nasal cavity, paranasal sinuses and nasopharynx. Cancer 1979; 43:611-21.

${ }^{13}$ Michaels L, Gregory MM. Pathology of "non-healing (midline) granuloma”. J Clin Pathol 1977;30:317-27.

${ }^{14}$ Huhn D, Meister P. Malignant histiocytosis. Morphologic and cytochemical findings. Cancer 1978;42:1341-9.

${ }^{15}$ Lampert IA, Catavosky D, Bergier N. Malignant histiocytosis: A clinicopathologic study of 12 cases. $\mathrm{Br} J$ Haematol 1978;40:65-77.

16 Lukes RJ, Collins RD. Immunologic characterisation of human malignant lymphomas. Cancer 1974;34:14881503.

${ }^{17}$ De Faria JL, Cutin M, Morgante AP, Ferri RG. Malignant granuloma of the face: Contributions to its nosology. Arch Otolaryngol 1957;65:255-62.

${ }_{18}$ Isaacson P, Wright DH. Malignant histiocytosis of the intestine. Its relationship to malabsorption and ulcerative jejunitis. Hum Pathol 1978;9:661-77.

19 Isaacson P, Wright DH. Intestinal lymphoma associated with malabsorption. Lancet $1978 ; \mathrm{i}: 67-70$.

${ }^{20}$ Godman GC, Churg J. Wegener's granulomatosis, pathology and review of the literature. Arch Pathol 1954; 58:533-53.

${ }^{21}$ Liebow AA, Carrington CRB, Friedman PJ. Lymphomatoid granulomatosis. Hum Pathol 1972;3:457-558.

${ }^{22}$ Katzenstein A-L, Carrington CRB, Liebow AA. Lymphomatoid granulomatosis. A clinicopathologic study of 152 cases. Cancer 1979;43:360-73.

${ }^{23}$ Crissman JD. Midline malignant reticulosis and lymphomatoid granulomatosis. Arch Pathol 1979;103:561-4.

24 Lipper S, Wheeler MS, Jennete C. Malignant pulmonary lymphoproliferative angitis. Cancer 1980;46:1411-7.

${ }^{25}$ Kay S, Fu Y-S, Minars N, Brady JW. Lymphomatoid granulomatosis of the skin. Light microscopic and ultrastructural studies. Cancer 1974;34:1675-82.

26 Hammar S-P, Gortner D, Sumida S. Lymphomatoid granulomatosis: association with retroperitoneal fibrosis of the evidence of impaired cell-mediated immunity. Am Rev Respir Dis 1977;115:1045-50.

27 Pena GE. Lymphomatoid granulomatosis with cerebral involvement Light and electron microscopic study of a case. Acta Neuropathol 1977;37:193-7.

${ }^{28}$ Bender BL, Jaffe R. Immunoglobulin production in lymphomatoid granulomatosis and relation to other "benign" lymphoproliferative disorders. Am J Clin Pathol 1980;73:41-7.

Requests for reprints to: Dr K Aozasa, Osaka University, Faculty of Medicine, Department of Pathology, Nakanoshima 4-chome 3-57, Kita-Ku, Osaka, 530 Japan. 